\title{
Harpin of Pseudomonas syringae pv. phaseolicola Harbors a Protein Binding Site
}

\author{
Chun-Mei Li, ${ }^{1}$ Minna Haapalainen, ${ }^{1}$ Justin Lee, ${ }^{2}$ Thorsten Nürnberger, ${ }^{3}$ Martin Romantschuk, ${ }^{4}$ and \\ Suvi Taira ${ }^{1}$
}

\begin{abstract}
${ }^{1}$ General Microbiology, Department of Biological and Environmental Sciences, FI-00014 University of Helsinki, Finland; ${ }^{2}$ Department of Stress and Developmental Biology, Institute of Plant Biochemistry, Weinberg 3, D-06120 Halle/Saale, Germany; ${ }^{3}$ Eberhard-Karls-University Tübingen, Center of Molecular Biology of Plants, Plant Biochemistry, Auf der Morgenstelle 5, D-72076 Tübingen, Germany; ${ }^{4}$ Department of Ecological and Environmental Sciences, University of Helsinki, Niemenkatu 73, FI-15140 Lahti, Finland
\end{abstract}

Submitted 8 March 2004. Accepted 7 September 2004.

\begin{abstract}
Harpin HrpZ of plant-pathogenic bacterium Pseudomonas syringae elicits a hypersensitive response $(\mathrm{HR})$ in some nonhost plants, but its function in the pathogenesis process is still obscure. HrpZ-interacting proteins were identified by screening a phage-display library of random peptides. HrpZ of the bean pathogen $P$. syringae pv. phaseolicola $\left(\right.$ HrpZ $\left._{\mathrm{Pph}}\right)$ shows affinity to peptides with a consensus amino acid motif $W(L) A R W L L(G / L)$. To localize the peptidebinding site, the $h r p Z_{\mathrm{Pph}}$ gene was mutagenized with randomly placed 15-bp insertions, and the mutant proteins were screened for the peptide-binding ability. Mutations that inhibited peptide-binding localized to the central region of $h r p Z_{\mathrm{Pph}}$, which is separate from the previously determined HR-inducing region. Antiserum raised against one of the $h r p Z_{\mathrm{Pph}}$-binding peptides recognized small proteins in bean, tomato, parsley, and Arabidopsis thaliana but none in tobacco. On native protein blots, $h r p Z_{\mathrm{Pph}}$ bound to a bean protein with similar $\mathrm{pI}$ as the protein recognized by the peptide antiserum. The result suggests a protein-protein interaction between the harpin and a host plant protein, possibly involved in the bacterial pathogenesis.
\end{abstract}

Additional keywords: functional domains, HrpN, type III secretion system.

Pseudomonas syringae can infect the aboveground parts of numerous plant species by entering the plant tissues through wounds or natural openings, such as stomata. When bacteria get inside the plant, bacterial genes encoding the components of the type III secretion system (TTSS) are induced (Boureau et al. 2002). A variety of co-regulated genes encode effector proteins that are secreted through this system and transported from the bacterial cell into the plant cell cytoplasm through a long pilus structure (Brown et al. 2001; Jin and He 2001; Li et al. 2002). The presumed function of the proteins delivered to the host cell via TTSS is to inhibit or suppress the host defense and thus promote bacterial survival and multiplication inside the host tissue (Galán and Collmer 1999). Accordingly, TTSS is essential for the ability of $P$. syringae to infect plants and to cause plant diseases (Roine et al. 1997).

One of the proteins secreted via TTSS is HrpZ, also referred to as harpin, which is not delivered into the host cytoplasm but

Corresponding author: M. Haapalainen; Telephone: +358-9-19159214; Fax: +358-9-19159262; E-mail: Minna.Haapalainen@helsinki.fi into the intercellular space. The function of HrpZ in the bacterial infection process is not known. At high concentrations, HrpZ induces a local programmed cell death called hypersensitive response (HR) in some nonhost plants (He et al. 1993; Preston et al. 1995). Tobacco (Nicotiana tabacum) has been favored as a test plant for HR induction by harpins, because it gives a strong and repeatable response. Interestingly, $P$. syringae pv. tabaci, which causes wild fire disease of tobacco, does not produce HrpZ but only carries a truncated, nonfunctional copy of the hrpZ gene (Taguchi et al. 2001). Thus, in tobacco, expression of HrpZ might be deleterious rather than beneficial for the bacterial pathogen. Each $P$. syringae pathovar seems to have developed an individual arsenal of proteins secreted through the TTSS (Charity et al. 2003); therefore, HrpZ also may have evolved to interact specifically with the plants included in the pathovar host range.

Results with in planta expression of HrpZ indicate an extracellular function: HrpZ elicits an HR only when localized in the apoplast, and not when localized inside the plant cells (Tampakaki and Panopoulos 2000). Moreover, HrpZ was localized in the outer part of the plant cell after application of the partially purified protein on tobacco cell-suspension culture (Hoyos et al. 1996). HrpZ is able to insert in lipid bilayers and to form ionconducting pores (Lee et al. 2001a and b), suggesting it would function on the host plasma membrane. HrpZ also has been shown to form multimers, up to octamers, in solution (Chen et al. 1998); therefore, it is possible that HrpZ could function as a membrane-associated complex. The harpin produced by Erwinia spp., encoded by the $h r p N$ gene (Wei et al. 1992), was shown to affect plasma membrane ion channels in Arabidopsis thaliana suspension cells (El-Maarouf et al. 2001). Surprisingly, the association of harpins, both HrpZ and HrpN, with plant cell membrane seems to be a reversible event (Lee et al. 2001a; Pike et al. 1998). The harpins could be involved in the release of nutrients from the host cell or they could assist in the delivery of other bacterial proteins into the host cell. Several animal-pathogenic bacteria which utilize the TTSS produce proteins that form a protein translocation complex in the host cell plasma membrane (Blocker et al. 1999; Håkansson et al. 1996). A TTSS-harboring plant pathogen, Xanthomonas campestris, also secretes a membrane-inserting protein, HrpF, which binds to lipids and shows a pore-forming activity. HrpF is essential for the interaction with the host plant, and it has been suggested to have a translocation function (Büttner et al. 2002). Despite the lack of protein sequence homology, HrpZ might have an analogous function as a part of the TTSS. 
Whether the harpins interact with host proteins during the infection process is not known. Because $P$. syringae produces several harpin-like proteins, the function of HrpZ in pathogenesis is difficult to determine: a simple hrpZ mutant has no clear effect on HR induction in nonhost plants (Charkowski et al. 1998) or on virulence in host plants (Lee et al. 2001b). Yet HrpZ is produced by all but one of the $P$. syringae pathovars that have been characterized at the molecular level, and the sequence of this protein is highly conserved in the different pathovars, suggesting an unknown but possibly important pathogenesis-promoting function. HrpZ probably exerts its function as an integral membrane protein; therefore, the possible interactions between HrpZ and host proteins are likely to take place within the lipid environment. Thus, the putative interactions might be hidden by the lipids and hard to detect directly. We chose an indirect method to study the protein-binding characteristics of HrpZ involving the affinity of random peptides displayed on phage particles, and localized the peptide-binding site of HrpZ in a central region of the protein sequence using a defined set of the HrpZ mutant proteins.

\section{RESULTS}

\section{HrpZ $_{P p h}$ binds to a defined peptide sequence.}

Phage clones carrying a peptide with affinity to HrpZ of $P$. syringae $\mathrm{pv}$. phaseolicola race $6\left(\mathrm{Hrp}_{\mathrm{Pph}}\right)$ were enriched and isolated. The binding epitopes of 35 clones, confirmed by enzyme-linked immunosorbent assay (ELISA) to have a strong affinity for $\mathrm{Hrp} \mathrm{Z}_{\mathrm{Pph}}$, were sequenced. The sequences were found to encode only eight peptides (Table 1,1 to 8 ), which are strikingly similar, all containing a hydrophobic amino acid motif with tryptophan and leucine, the consensus being W(L)ARWLL(G/L). The similarity of the peptide sequences suggests that $\mathrm{HrpZ}_{\mathrm{Pph}}$ has a binding site for a protein and not just for any hydrophobic molecule. However, no sequences with a perfect match to the consensus peptide were found in the available sequence databases.

\section{Peptide-binding site maps}

in the middle of the $\mathrm{HrpZ}_{\mathrm{Pph}}$ sequence.

To locate the peptide-binding site within $\mathrm{HrpZ}_{\mathrm{Pph}}$, a library of randomly distributed 5-amino-acid (aa) insertion mutations on $\mathrm{HrpZ}_{\mathrm{Pph}}$ was constructed. We developed an assay for determining the peptide-binding affinity of large amounts of semipurified harpin preparations, and screened the insertion mutants for loss of binding to the phage-displayed peptides 1 and 3 (Table 1). Of 276 mutants screened, we found 12 distinct nonbinding mutants (Fig. 1A). Sequencing revealed that all of the inhibiting mutations resided in the central part of $\mathrm{HrpZ}_{\mathrm{Pph}}$, between amino acids 86 and 194. However, all mutations within this region, which might be called the peptide-binding domain, did not block binding: several noninhibiting insertion mutations were localized between the inhibiting mutations (Fig. 1B).
Interestingly, this domain includes a region of homology common to all of the HrpZ proteins and HrpN harpin of Erwinia and Pantoea spp. A short homology, within 22 aa, between $\mathrm{HrpZ}$ of $P$. syringae pv. syringae $\left(\mathrm{HrpZ}_{\mathrm{Pss}}\right)$ and $\mathrm{HrpN}$ of Erwinia amylovora, was described previously by $\mathrm{He}$ and associates (1993), but we found that the homology extends over 69 to 85 aa (Fig. 2A). In addition to this conserved region, both HrpZ and HrpN have a domain with a low-complexity amino acid sequence rich in glycine, which is characteristic for harpins. In the HrpZ sequence, the glycine-rich domain is downstream of the conserved region; however, in $\operatorname{HrpN}$, it is on the N-terminal side (Fig. 2B). Thus, HrpZ and HrpN seem to have two similar domains but in an inverse order.

\section{HrpZ of $P$. syringae pv. syringae shows affinity to the $\operatorname{HrpZ}_{\mathbf{P p h}}$-binding peptides.}

Harpins of other $P$. syringae pathovars, which have a different host range, and also HrpN harpin of a soft-rotting plant pathogen E. carotovora subsp. carotovora, were assayed to see if these proteins would have the same peptide-binding specificity as $\mathrm{HrpZ}_{\mathrm{Pph}}$. HrpZ $\mathrm{Z}_{\mathrm{Pss}}$ bound the phage-displayed peptides number 1 and 3 , although with lower affinity than $\mathrm{HrpZ}_{\mathrm{Pph}}$, whereas HrpZ of $P$. syringae pv. tomato strain DC3000 $\left(\mathrm{HrpZ} \mathrm{Z}_{\mathrm{Pto}}\right.$ ) did not bind (Fig. 3). For HrpZ $\mathrm{Pph}_{\mathrm{Ph}}$ and $\mathrm{HrpZ}_{\mathrm{Pto}}$, of which both semipurified and purified samples were available, the peptide-binding affinities of the preparations with different purity level were equal, indicating that impurities originating from Escherichia coli did not interfere with the peptide binding. Thus, the lower binding affinity showed by HrpZ $Z_{\text {Pss }}$ probably was caused by the sequence differences between HrpZ $Z_{\mathrm{Pss}}$ and $H r p Z_{\mathrm{Pph}}$, and not by other molecules present in the different harpin samples. HrpN had only a very weak interaction with the $\mathrm{HrpZ}_{\mathrm{Pph}}$-binding peptides, suggesting that this harpin, if binding to peptides, is likely to have a different binding specificity.

\section{Antiserum raised against peptide 3 recognized plant proteins.}

In order to find the protein that corresponds to the consensus peptide discovered via phage display, rabbits were immunized with the HrpZ $\mathrm{Pph}_{\mathrm{Pp}}$-binding peptides 1 and 3 , and the antisera were used to probe proteins of bacterial and plant origins. Chemical crosslinking experiments have indicated oligomerization of $\mathrm{HrpZ}_{\mathrm{Pph}}$ (J. Lee and T. Nürnberger, unpublished data) and $\mathrm{HrpZ}_{\mathrm{Pph}}$ itself has a tryptophan within the region where insertions inhibit peptide-binding; therefore, it is possible that oligomerization of the harpin might constitute the consensus peptide epitope. Thus, we first tested the peptide 3 antiserum for binding to immobilized HrpZ on Western blots, but the result was negative. However, when peptide number 3 was allowed to bind to the immobilized harpin in an overlay assay (far-Western) and then probed with the antiserum, the HrpZ band was revealed (data

Table 1. Phage-displayed peptides with a strong affinity to HrpZ of Pseudomonas syringae pv. phaseolicola race $6^{\mathrm{a}}$

\begin{tabular}{lccc}
\hline Peptide no. & Amino acid sequence of the displayed peptide & Detection limit & Number of clones \\
\hline 1 & PWLGLWLLGV & $10^{4}$ & 1 \\
2 & PWLARWLLGV & $10^{4}$ & 1 \\
3 & WARWLLLTPA & $10^{4}$ & 4 \\
4 & FVRWLLLGVP & $10^{6}$ & 9 \\
5 & DTWARWML & $10^{6}$ & 1 \\
6 & LGCWILPRL & $10^{7}$ & 1 \\
7 & SWALWMLG & $10^{7}$ & 14 \\
8 & WLGLMRW & $10^{8}$ & 4 \\
Consensus & W(L)ARWLL(G/L) & $\ldots$ & $\ldots$ \\
\hline
\end{tabular}

${ }^{a}$ Detection limit denotes the number of phage particles required for a positive signal in enzyme-linked immunosorbent assay. Number of clones refers to the frequency in which the clones with an identical insert sequence were isolated. The central tryptophanof the $\mathrm{HrpZ}_{\mathrm{Pph}}$-binding peptides is shown in bold. 
not shown). Thus, the result that the peptide 3 antiserum did not recognize the immobilized harpin was not caused by a damage of the harpin or lack of renaturation. As a whole, this indicates that the peptide-binding site is not mediating dimerization or oligomerization of HrpZ but, rather, an interaction of HrpZ with some other protein. Moreover, the peptide antisera also did not bind to protein samples of Hrp-induced $P$. syringae pv. phaseolicola, and an overlay (far-Western) with HrpZ did not reveal any interactions with the Hrpinduced bacterial proteins.

In addition to the proteins secreted by $P$. syringae, protein extracts of the host plant, bean, and four nonhost plants of $P$. syringae pv. phaseolicola were probed with the peptide anti- sera. Peptide 3 antiserum recognized small (13- to 20-kDa) proteins in bean, tomato, $A$. thaliana, and parsley, but not in tobacco samples (Fig. 4A). Binding of the antibodies to the small proteins could be inhibited by pre-incubation of the peptide 3 antiserum (diluted 1:1000) with free peptide 3 (2 $\mu \mathrm{g} / \mathrm{ml})$. The complete blocking of antibody-binding by the peptide indicates that the small plant proteins are recognized by the same antibodies specific for peptide 3. To further characterize the peptide 3 cross-reacting proteins, the plant protein samples also were run on nondenaturing isoelectric focusing gels (IEF gels). The proteins found in bean, tomato, and parsley were very acidic, with pI 4.0 to 4.4 , whereas the pI of the $A$. thaliana protein was 5.8 to 6.3 . In protein sam-

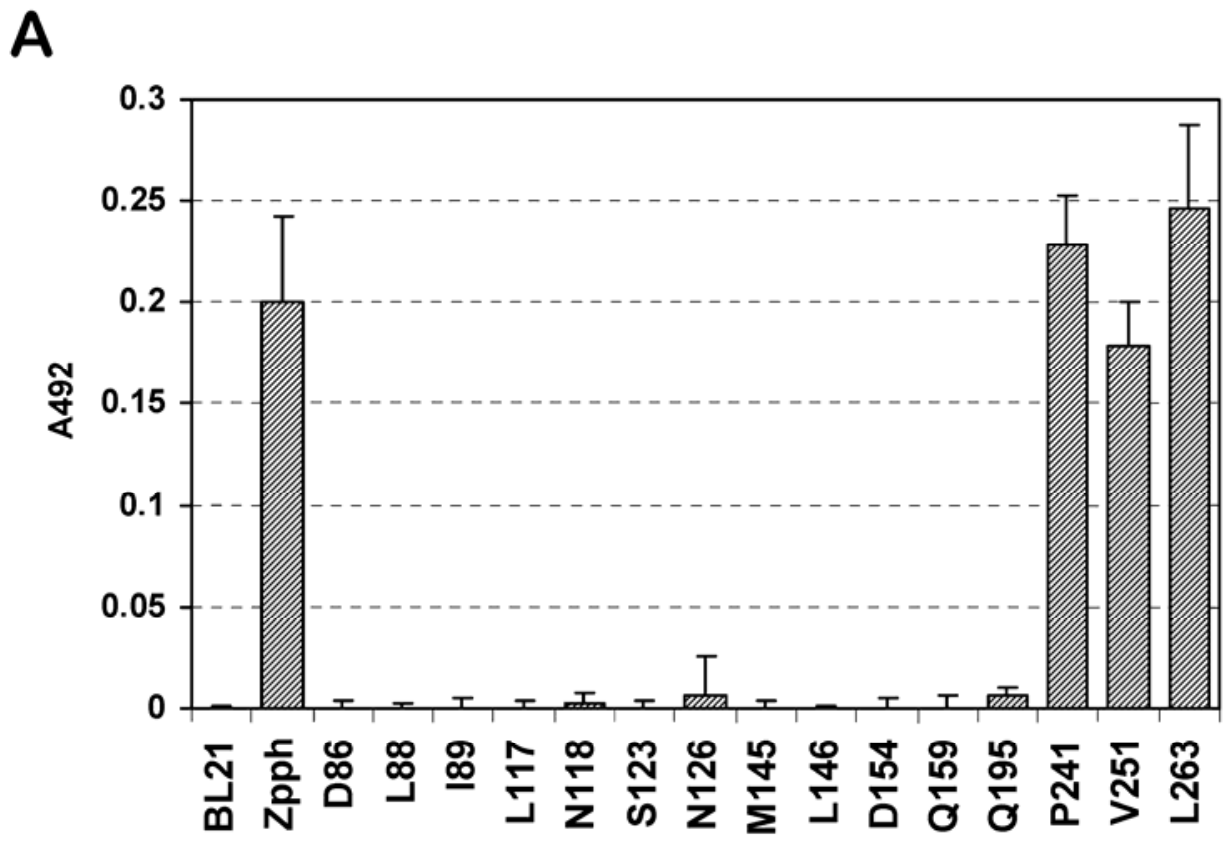

B

MQSLSLNSSTLQSPSMALVLIRPETETTGSSTSSRALQEVIAQLAQELTHNGQLDESSPL
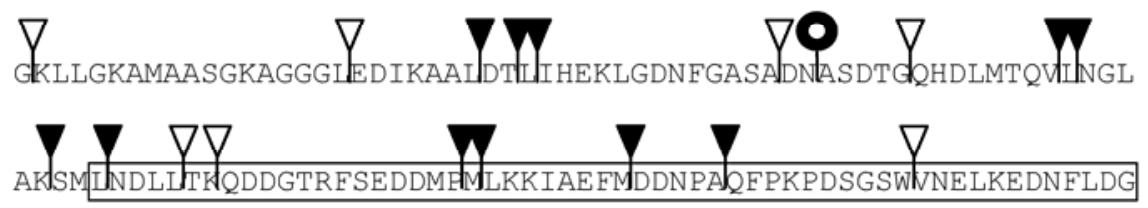

Fig. 1. Binding of phage-displayed peptides to intact harpin and harpin mutants. A, Binding of phage peptide 3 to HrpZ of Pseudomonas syringae pv. phaseolicola race $6\left(\mathrm{HrpZ}_{\mathrm{Pph}}\right)$ and the insertion mutants was determined by enzyme-linked immunosorbent assay with color development, absorbing light at $492 \mathrm{~nm}$ (A492). BL21, background, protein preparation from Escherichia coli with no harpin expression; ZPph, intact recombinant HrpZ from P. syringae pv. phaseolicola; D86-L263, HrpZ ${ }_{\mathrm{Pph}}$ mutants carrying a 5-amino-acid (aa) insertion, named after the symbol and position of the amino acid affected by the insertion. B, Localization of the peptide-binding site of HrpZ $\mathrm{Pph}_{\mathrm{ph}}$ by scanning insertion mutagenesis. Locations of the insertions that inhibit peptide-binding (Fig. 1A) are indicated on the sequence by black arrowheads and noninhibiting insertions are indicated by open arrowheads. HrpZ of $P$. syringae pv. tomato strain DC3000, which does not bind the peptides, contains a 24-aa-long extension not found in the other HrpZ proteins. The location of this extension is marked on the $\mathrm{HrpZ}_{\mathrm{Pph}}$ sequence with a black ring. The region conserved in all the HrpZ and HrpN proteins is framed, and the hypersensitive responseinducing region is bold. The conserved repeats found in all HrpZ proteins are underlined. 
ples from tobacco, no peptide 3 cross-reacting protein was detected on the IEF gel blots. The fact that the proteins seen in the native IEF blots were the same as the proteins detected from the sodium dodecyl sulfate-gel electrophoresis (SDSPAGE) blots was confirmed by cutting the IEF gel into thin strips and extracting the proteins. These fractions were run on SDS-PAGE and then were blotted and probed with peptide 3 antiserum. This experiment was carried out with bean and $A$. thaliana protein samples and, in both cases, the result was positive: a $20-\mathrm{kDa}$ protein of bean and a $13-\mathrm{kDa}$ protein of A. thaliana were detected from the final blot.

\section{HrpZ $_{\mathrm{Pph}}$ binds to an acidic, heat-sensitive protein of bean.}

To verify whether the small acidic proteins identified above could directly interact with $\mathrm{HrpZ}_{\mathrm{Pph}}$, far-Western experiments were performed. The plant protein samples were run on nondenaturing isoelectric focusing gel, blotted onto polyvinylidene difluoride (PVDF) membrane, overlayed with $\mathrm{HrpZ}_{\mathrm{Pph}}$, and probed with HrpZ antiserum. Interestingly, the results showed binding of $\mathrm{HrpZ}_{\mathrm{Pph}}$ to an acidic protein band of bean that was running in the gel at exactly the same position as the protein recognized by the peptide 3 antiserum. In- stead, the acidic parsley proteins recognized by the peptide antiserum were not bound by $\mathrm{HrpZ}_{\mathrm{Pph}}$ (Fig. 4B). With tomato and $A$. thaliana native protein blots, the result was similarly negative for harpin binding. Protein samples of the five plant species, originally containing both soluble proteins and membrane proteins on membrane micelles, were extracted further with chloroform-methanol mix to remove lipids and lipophilic compounds. The peptide 3 crossreacting proteins of bean, tomato, parsley, and A. thaliana partitioned into the aqueous phase, and their $\mathrm{pI}$ was not shifted by the extraction process (Fig. 4B), suggesting that major conformational changes had not occurred. The fact that both the peptide antiserum recognition and $\mathrm{HrpZ}_{\mathrm{Pph}}$-binding were not affected by the removal of lipids from the bean sample suggests that the interacting factors are hydrophilic proteins. Heating of the bean protein samples, with or without lipids, to $100^{\circ} \mathrm{C}$ for 10 min resulted in a pI change close to 5.0 of the peptide 3 crossreacting protein, and the loss of binding by HrpZ $\mathrm{Z}_{\mathrm{Pph}}$ (data not shown). Taking this together with the fact that $\mathrm{HrpZ}_{\mathrm{Pph}}$ did not bind to denatured proteins blotted from SDSPAGE, we can conclude that the native fold of the bean protein is essential for the interaction with the harpin.

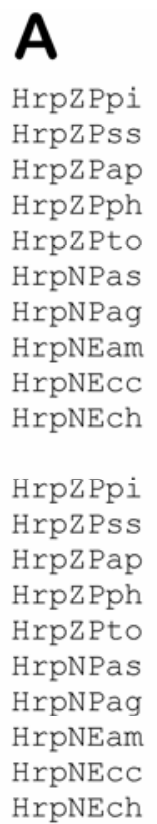

B

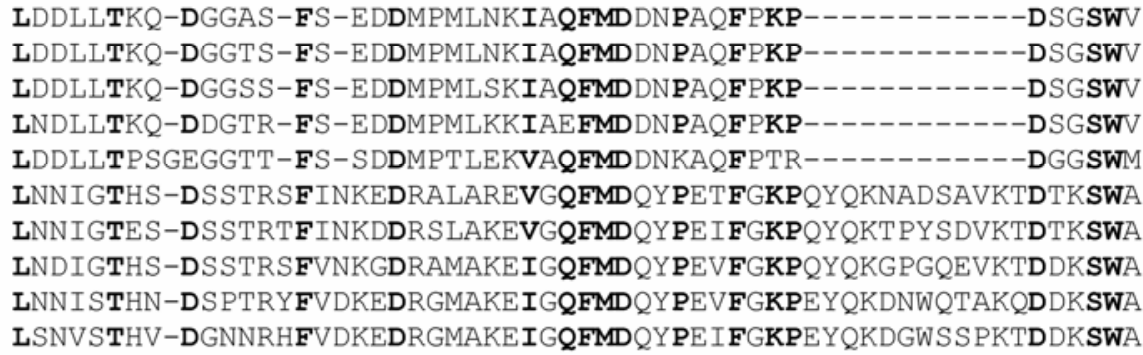

$$
\begin{aligned}
& 125-193 \\
& 124-192 \\
& 125-193 \\
& 125-193 \\
& 148-217 \\
& 253-337 \\
& 253-337 \\
& 274-358 \\
& 228-312 \\
& 211-295
\end{aligned}
$$

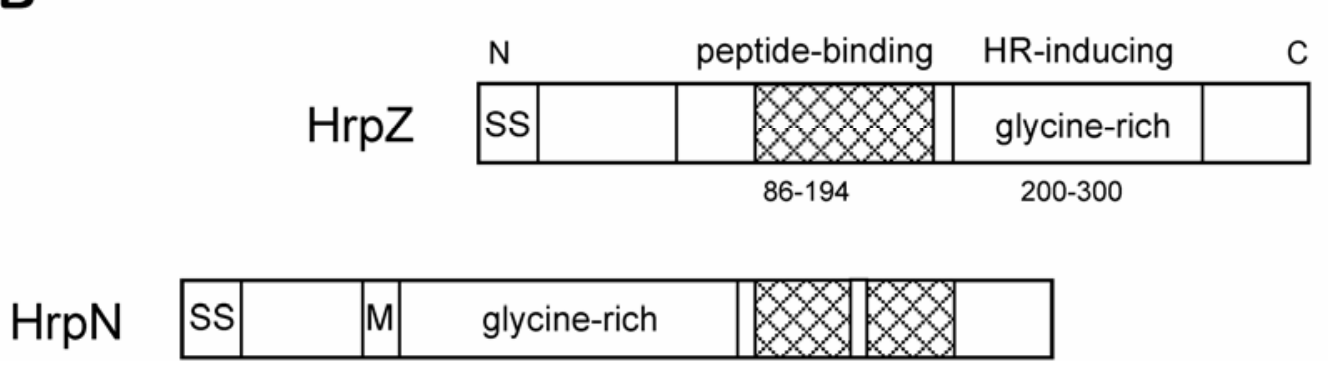

Fig. 2. Domains of harpins HrpZ and HrpN. A, Sequence alignment of the homologous domains of HrpZ (Pseudomonas) and HrpN (Erwinia and Pantoea). This domain is located centrally in HrpZ protein sequence and near the N-terminus in HrpN. The alignment was produced by using CLUSTAL W (1.82) program with Blosum matrix. The most conserved amino acids are shown in bold, and the numbers following each sequence refer to the position of the amino acids shown, counted from the N-terminus of each protein. The abbreviations for species names are: Ppi, Pseudomonas syringae pv. pisi; Pss, P. syringae pv. syringae; Pap, P. syringae pv. aptata; Pph, P. syringae pv. phaseolicola; Pto, P. syringae pv. tomato (strain DC3000); Pas, Pantoea stewartii subsp. stewartii; Pag, P. agglomerans pv. gypsophilae; Eam, Erwinia amylovora; Ecc, E. carotovora subsp. carotovora; and Ech, E. chrysanthemi. B, Functional domains of $\mathrm{HrpZ}$ of Pseudomonas syringae pv. phaseolicola race $6\left(\mathrm{HrpZ}_{\mathrm{Pph}}\right)$ and $\mathrm{HrpN}$ of E. amylovora $\left(\mathrm{HrpN} \mathrm{Nam}_{\mathrm{Eam}}\right)$. The type III secretion signal (SS) supposedly resides at the N-terminus, either in the amphipathic amino acid sequence or in the messenger RNA. Like most of the HrpN proteins, HrpN $\mathrm{Nam}_{\text {Eam }}$ contains a polymethionine stretch (M). The region that is homologous between $\mathrm{HrpZ}$ and $\mathrm{HrpN}$ is crosshatched. 


\section{DISCUSSION}

To find out whether HrpZ is interacting with proteins, in addition to the previously confirmed interaction with lipids, we studied the binding of random phage-displayed peptides to $\mathrm{HrpZ}_{\mathrm{Pph}}$. By using this method, we discovered that $\mathrm{HrpZ} \mathrm{Z}_{\mathrm{Pph}}$ binds peptides which contain tryptophan and leucine. The eight peptide sequences found could be aligned to define a consensus sequence W(L)ARWLL(G/L). The similarity of the $\mathrm{HrpZ}_{\mathrm{Pph}}$-binding peptides suggests that these peptides correspond to a protein epitope; a collection of unrelated (hydrophobic) sequences would, instead, indicate binding of $\mathrm{HrpZ}_{\mathrm{Pph}}$ to any hydrophobic molecule, which could be either a protein or a lipid.

To localize the peptide-binding site of $\mathrm{HrpZ}_{\mathrm{Pph}}$, we performed scanning insertion mutagenesis of $h r p Z$ gene. Screening the mutated proteins for peptide binding showed that inhibiting mutations all were located within the same region in the $\mathrm{HrpZ}_{\mathrm{Pph}}$ sequence. This region is fairly large, covering a stretch of at least 108 aa; therefore, the peptide-binding site probably is formed by multiple amino acid residues distant from each other in the primary structure. This interpretation is supported by the presence of several noninhibiting mutations between the inhibitory mutations. The inhibiting insertion mutations may either block the peptide binding surface or interfere with the protein folding. It is noteworthy that these mutations reside in a region distinct from that deduced to act as an HR elicitor, which was previously located between amino acids 200 and 300 (Lee et al. 2001a). In accordance with this previous result, none of the peptide-nonbinding mutants were impaired in the ability to induce HR on tobacco leaves (data not shown). Hence, we identified protein-protein interaction here that probably is not involved in the induction of HR by HrpZ but might contribute to the compatible pathogen-host interaction. The maintenance of HrpZ and related sequences in various $P$. syringae genomes is highly indicative of an important function during the bacterial infection. A likely candidate is the pore-forming activity (Lee et al. 2001b). The full-length protein as well as either termini of HrpZ were capable of attaching to proteinfree, lipid-coated silica beads (Lee et al. 2001b), but only the intact protein was able to form ion-conducting pores (unpublished data). Thus, attachment of HrpZ to lipids may be brought about by the termini, whereas the central domain may interact with a proteinaceous compound, as we have shown here. In conclusion, HrpZ $\mathrm{P}_{\mathrm{Ph}}$ seems to consist of several functional do- mains. The extreme N-terminal sequence probably contains the secretion signal for TTSS, the highly conserved central domain harbors a peptide binding site, and the $\mathrm{N}$ - and $\mathrm{C}$-termini assist in membrane integration for pore formation. In addition, the accessible $\mathrm{C}$-terminal region acts as an elicitor of defense responses in some resistant plants.

The variation in peptide-binding affinities shown by the HrpZ proteins of different $P$. syringae pathovars suggests that the harpins could be differentially interacting with a putative host-specific protein. Interestingly, $\mathrm{HrpZ}$ of the tomato pathovar did not show any binding affinity to the HrpZ $\mathrm{Z}_{\mathrm{Pph}}$-binding peptides. In addition to overall sequence divergence, HrpZ $Z_{\mathrm{Pto}}$ carries a 24-aa stretch not found in the other HrpZ proteins, and this extension is located within the region that is responsible for the peptide-binding in $\mathrm{HrpZ} \mathrm{Z}_{\mathrm{Pph}}$. The extension sequence is homologous with the corresponding region of PopA1, a distantly related harpin produced by another tomato pathogen, Ralstonia solanacearum (Arlat et al. 1994). If the central region of $\mathrm{HrpZ}_{\mathrm{Pto}}$ and PopA1 mediates an interaction with a host protein, one could assume that this protein would be different from the one interacting with $\mathrm{HrpZ}_{\mathrm{Pph}}$.

When plant protein samples were probed with antiserum raised against the $\mathrm{HrpZ} \mathrm{Z}_{\mathrm{Pph}}$-binding peptide 3, the antiserum recognized small and acidic proteins in bean, tomato, parsley, and Arabidopsis leaf protein samples. The peptide 3-specific antibodies recognized these plant proteins on both SDS-PAGE blots and native IEF gel blots, whereas $\mathrm{HrpZ}_{\mathrm{Pph}}$ did not bind to denatured proteins. Under nondenaturing conditions, $\mathrm{HrpZ}_{\mathrm{Pph}}$ bound to a bean protein, as acidic as the peptide 3 crossreacting protein. This interaction was not disturbed but strengthened after extraction of the lipids from the bean sample, which further supports our conclusion that $\mathrm{HrpZ}_{\mathrm{Pph}}$ binds to a host protein. Whether the protein recognized by the peptide antiserum is the same protein bound by the harpin is still unclear. Any proteins of tomato, parsley, and Arabidopsis having similar $\mathrm{pI}$ as the peptide 3 crossreacting proteins were not bound by $\mathrm{HrpZ}_{\mathrm{Pph}}$; therefore, we can conclude that a peptide 3 -like epitope on a protein is not adequate for interaction with $\mathrm{HrpZ}_{\mathrm{Pph}}$. The epitope conformation could be incorrect or the surrounding protein structures could hinder the interaction. Therefore, the protein-binding site of $\mathrm{HrpZ}_{\mathrm{Pph}}$ probably is not completely defined by the binding studies performed with short phage-displayed peptides. The fact that $\mathrm{HrpZ}_{\mathrm{Pph}}$ tolerates some sequence variation in the bound peptides also suggests that the binding surface in the corresponding protein might be

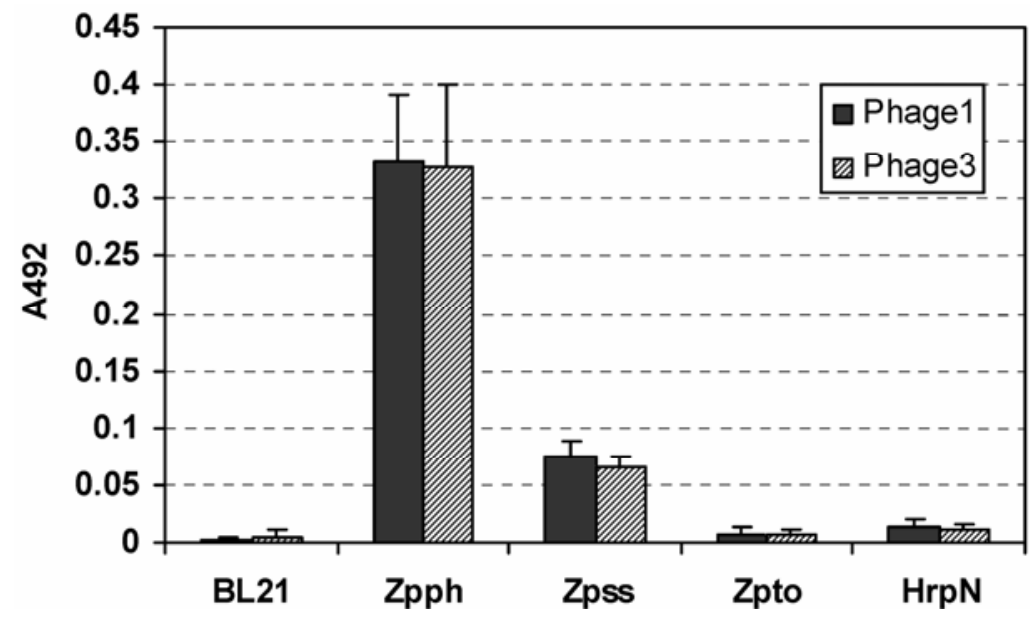

Fig. 3. Binding of phage-displayed peptides 1 and 3 to different harpins. BL21, background; ZPph, ZPss, and ZPto, full-length HrpZ of Pseudomonas syringae pvs. phaseolicola, syringae, and tomato, respectively; HrpN, harpin of Erwinia carotovora subsp. carotovora SCC1. Data for both phages were combined of the results of four assays, each with at least four replicates of each protein sample. Each protein was applied on enzyme-linked immunosorbent assay plate at $50 \mathrm{ng} / \mathrm{well}$. 
formed by a structure larger than 8 aa. However, it seems that peptide 3 corresponds to an epitope present in a group of small and acidic plant proteins, and that $\mathrm{HrpZ}_{\mathrm{Pph}}$ binds in a host-specific manner to a protein showing similar characteristics.

\section{MATERIALS AND METHODS}

\section{Harpin expression and purification.}

$\mathrm{HrpZ}_{\mathrm{Pph}}$ and HrpZ $\mathrm{Z}_{\mathrm{Pto}}$ were expressed by IPTG (isopropyl- $\beta$ D-thiogalactoside) induction in Escherichia coli strain BL21 (DE3) pLysS from vector pJC40 as previously described (Lee et al. 2001a and b). hrpN of Erwinia carotovora subsp. carotovora strain SCC1 (Rantakari et al. 2001) was amplified by polymerase chain reaction (PCR) (forward primer, 5'-GAGGAAA TCATATGCTTAATTCTCT-3' and reverse primer, 5'-CTCAA GCTTGGCTTTAGCTGGA-3') and inserted into pJC40. HrpN was expressed from this construct, pJCHRPN, similarly as $\mathrm{HrpZ}_{\mathrm{Pph}}$ and $\mathrm{HrpZ}_{\mathrm{Pto}}$, whereas HrpZ $\mathrm{Z}_{\mathrm{Pss}}$ was expressed from pSYH10 (He et al. 1993). After 4 h of induction, the Escherichia coli cells were harvested and then frozen at $-20^{\circ} \mathrm{C}$, thawed, and resuspended in lysis buffer $(50 \mathrm{mM}$ Tris- $\mathrm{HCl}, \mathrm{pH} 8.0,1$ $\mathrm{mM}$ EDTA, and lysozyme at $0.8 \mathrm{mg} / \mathrm{ml}$ ). After incubation at room temperature for $15 \mathrm{~min}$, the suspensions were heated at $100^{\circ} \mathrm{C}$ for $10 \mathrm{~min}$ and centrifuged at $16,000 \times g$ at $4^{\circ} \mathrm{C}$ for 20 min. Although most of the other proteins were precipitated, HrpZ remained in the supernatant, which was used as a semipurified harpin preparation. Cells expressing His-tagged HrpN were resuspended in $6 \mathrm{M}$ guanidine $\mathrm{HCl} / 0.1 \mathrm{M} \mathrm{NaH}_{2} \mathrm{PO}_{4} / 10$ $\mathrm{mM}$ Tris- $\mathrm{HCl}, \mathrm{pH} 8.0$, and not heated but applied directly on Ni-NTA agarose (Qiagen, Hilden, Germany), then purified under denaturing conditions according to the manufacturer's protocol. For comparing the peptide-binding affinity, the Histagged $\mathrm{HrpZ}_{\mathrm{Pph}}$ and $\mathrm{HrpZ}_{\mathrm{Pto}}$ also were purified by using $\mathrm{Ni}$ NTA agarose, under native conditions.

\section{Phage display.}

Peptides binding to HrpZ $\mathrm{Z}_{\mathrm{Pph}}$ were screened by using a phage display technique (Koivunen et al. 2001). Random peptides, a library of $10^{8}$ to $10^{10}$ different sequences, were inserted to the minor capsid protein PIII of a filamentous bacteriophage fUSE5. Three pools of such libraries with peptides displayed on the surface of the phage particles were screened. Pool I was composed of four libraries of linear 7- to 11-aa peptides and pool II of three libraries of 9- to 12-aa peptides crosslinked via terminal cysteines, and pool III contained a mix of five libraries with both linear and crosslinked peptides, 8 to 10 aa long. Microtiter plates were coated with $\mathrm{HrpZ}_{\mathrm{Pph}}, 50 \mathrm{ng} /$ well, and blocked with bovine serum albumin. The coated plates were incubated with the phage library pools, and the bound phage particles were used for infecting E. coli K91/kan cells as described by Koivunen and associates (2001). Phage particles were harvested from the $E$. coli culture supernatant and used for the next round of panning. After four rounds, HrpZ-binding phage clones were picked and the DNA inserts encoding the displayed peptides were amplified by PCR and sequenced. ELISA was used to confirm that the selected phages truly bind to $\mathrm{HrpZ}_{\mathrm{Pph}}$. The bound phage particles were detected with M13specific monoclonal antibody and anti-mouse antibody conjugated to horseradish peroxidase (Dako, Glostrup, Denmark). Color reaction with $o$-phenyllenediamine (OPD tablets; Sigma, St. Louis) allowed us to rate the $\mathrm{HrpZ}_{\mathrm{Pph}}$ affinity of the phagedisplayed peptides by reading absorbance at $492 \mathrm{~nm}$.

\section{HrpZ mutants.}

The hrpZ gene of $P$. syringae pv. phaseolicola was mutagenized with a mini-Mu transposon, according to the protocol of the Mutation Generation System kit (Finnzymes,
Espoo, Finland). Insertion and subsequent deletion of the transposon created 15-bp insertions in the target gene, resulting in 5 -aa insertions in the encoded protein. Mutated HrpZ proteins were expressed in E. coli BL21 similarly as was the intact protein. Each clone was grown in 1-ml volume and the cells were resuspended in $100 \mu \mathrm{l}$ of lysis buffer. The HrpZ concentration of each semipurified protein preparation was determined by SDS-PAGE analysis. Samples of each preparation were applied on microtiter plates and screened for binding the phage-displayed peptides 1 and 3 by using ELISA as described above. To test whether the mutations affected HR-elicitation by HrpZ, $20-\mu \mathrm{g}$ samples of the semipurified mutant proteins were injected into tobacco (cv. Samsun) leaves.

\section{Peptide antisera.}

Peptides number 1, 2, and 3 were synthesized on an ABIMED Economy Peptide Synthesizer (model EPS221; Langenfeld, Germany) according to the manufacturer's instructions. The quality of peptides was checked by MALDI-TOF mass spectrometry analysis. Rabbits were immunized with the synthetic peptides 1 and 3 , which had been conjugated via the terminal cysteine residues to keyhole limpet hemocyanin (KLH kit; Pierce, Rockford, IL, U.S.A.). Peptide 1 antiserum was found specific for peptides 1 and 2, and peptide 3 antiserum was specific for peptide 3 in ELISA.

\section{Extraction and immunoblotting of plant proteins.}

To extract plant proteins, leaves of bean (Phaseolus vulgaris cv. Red Mexican), tomato (Lycopersicon esculentum cv. Agriset), tobacco (N. tabacum cv. Samsun), parsley (Petro-

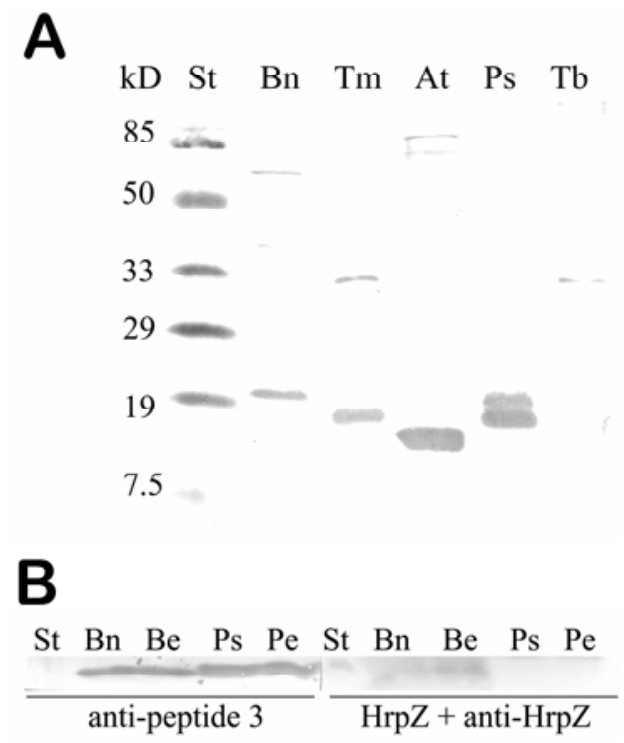

Fig. 4. Western blots of proteins extracted from plant leaves. A, Plant proteins were run on a denaturing gel (sodium dodecyl sulfate-gel electrophoresis [SDS-PAGE]) and the blot was probed with peptide 3 antiserum. St, prestained broad range SDS-PAGE standards (Bio-Rad); Bn, bean; Tm, tomato; At, Arabidopsis thaliana; Ps, parsley; and Tb, tobacco leaf extract. Estimated sizes of the peptide 3 cross-reacting proteins are 20,17, and 13 kDa for bean, tomato, and Arabidopsis proteins, respectively, and 19 and $17 \mathrm{kDa}$ for the two parsley proteins. The $32-\mathrm{kDa}$ bands in tomato and tobacco sample lines are nonspecific, and the 65-kDa band in the bean sample is a KLH cross-reacting protein. B, Plant protein samples $(20 \mu \mathrm{l})$ were run on a nondenaturing isoelectric focusing (IEF) gel, blotted under nondenaturing conditions, and probed with peptide 3 antiserum or HrpZ of Pseudomonas syringae pv. phaseolicola race 6. St, IEF standards pI 4.45 to 9.6 (Bio-Rad), of which the phycocyanin bands (pI 4.45 to 4.75 ) are shown; Bn and Ps, primary protein extracts from bean and parsley leaves; $\mathrm{Be}$ and $\mathrm{Pe}$, bean and parsley primary protein extracts further extracted with chloroform/methanol to remove lipids. 
selinum crispum cv. Hamburger Schnitt), and A. thaliana (var. Colombia) were homogenized in $50 \mathrm{mM}$ MOPS-KOH buffer, $\mathrm{pH} 7.5$, containing $5 \mathrm{mM}$ EDTA, $330 \mathrm{mM}$ sucrose, $0.1 \%$ polyvinyl pyrrolidon, $5 \mathrm{mM}$ ascorbic acid, and $3 \mathrm{mM}$ dithiothreitol ( $1 \mathrm{~g}$ of fresh leaves per $2 \mathrm{ml}$ of buffer). The homogenate was filtered through Miracloth, and phenylmethylsulfonyl fluoride was added to $1 \mathrm{mM}$. The suspension was cleared by centrifugation at $13,000 \mathrm{rpm}$ in a microfuge for $15 \mathrm{~min}$, and the supernatant, containing water-soluble materials and microsomes with membrane proteins, was stored at $-70^{\circ} \mathrm{C}$. For preparing immunoblots, $10-\mu \mathrm{l}$ samples of the plant protein extracts were run on SDS-polyacrylamide gel and blotted onto PVDF membrane. After blocking with $2 \%$ Tween 20 in Tris-buffered saline (TBS) the membranes were incubated overnight with peptide antiserum, diluted $1: 1000$ in $0.05 \%$ Tween/TBS. Second, the membranes were incubated with mouse monoclonal anti-rabbit antibody, conjugated to alkaline phosphatase (Sigma), and the bound conjugate was detected by using BCIP/ NBT color-reaction (Promega Corp., Madison, WI, U.S.A.). Samples (10 to $20 \mu \mathrm{l}$ ) of the plant protein extracts also were run on nondenaturing IEF gels (IEF ready gels; Bio-Rad, Sundbyberg, Sweden), with $\mathrm{pH}$ ranging from 5 to 8 and 3 to 10 , according to the manufacturer's protocol, and blotted in $0.7 \%$ acetic acid onto the PVDF membrane, which then was blocked with $3 \%$ casamino acids in $0.05 \%$ Tween/TBS. When performing far-Western analysis, the blot was incubated overnight with $\mathrm{HrpZ}_{\mathrm{Pph}}$ at $0.5 \mu \mathrm{g} / \mathrm{ml}$, and subsequently with rabbit $\mathrm{HrpZ}$ antiserum, diluted 1:2000 in $0.05 \%$ Tween/TBS, for $4 \mathrm{~h}$. To remove lipids, the plant protein extracts were extracted further with cold chloroform/methanol mix $(2: 1)$, one-fifth of the volume. The samples were mixed with vortex for $2 \mathrm{~min}$, and centrifuged in a microcentrifuge at $10,000 \mathrm{rpm}$ for $10 \mathrm{~min}$ at $4^{\circ} \mathrm{C}$. The hydrophilic compounds, including water-soluble proteins, partitioned into the aqueous upper layer, whereas most proteins precipitated at the interface of the two phases, and lipophilic compounds partitioned into the organic solvent phase.

\section{ACKNOWLEDGMENTS}

The research performed at the University of Helsinki was financed by the Academy of Finland and the Helsinki Graduate School in Biotechnology and Molecular Biology. We thank E. Koivunen for providing the phage display libraries, I. Kilpeläinen for studying HrpZ by NMR spectroscopy, A. Rantakari for providing the $h r p$ cluster of E. carotovora, J. Elster for technical assistance in the peptide synthesis, and E. von Roepenack-Lahaye for the MALDI-TOF quality control.

\section{LITERATURE CITED}

Arlat, M., Van Gijsegem, F., Huet, J. C. Pernollet, J. C., and Boucher, C. A. 1994. PopA1, a protein which induces a hypersensitivity-like response on specific Petunia genotypes, is secreted via the Hrp pathway of Pseudomonas solanacearum. EMBO (Eur. Mol. Biol. Organ.) J. 13:543-553.

Blocker, A., Gounon, P., Larquet, E., Niebuhr, K., Cabiaux, V., Parsot, C., and Sansonetti, P. 1999. The tripartite type III secretion of Shigella flexneri inserts IpaB and IpaC into host membranes. J. Cell Biol. 147:683693.

Boureau, T., Routtu, J., Roine, E., Taira, S., and Romantschuk, M. 2002. Localization of hrpA-induced Pseudomonas syringae pv. tomato DC3000 in infected tomato leaves. Mol. Plant Pathol. 3:451-460.

Brown, I. R., Mansfield, J. W., Taira, S., Roine, E., and Romantschuk, M. 2001. Immunocytochemical localization of HrpA and HrpZ supports a role for the Hrp pilus in the transfer of effector proteins from Pseudomonas syringae pv. tomato across the host plant cell wall. Mol. PlantMicrobe Interact. 14:394-404.

Büttner, D., Nennstiel, D., Klüsener, B., and Bonas, U. 2002. Functional analysis of HrpF, a putative type III translocon protein from Xanthomonas campestris pv. vesicatoria. J. Bacteriol. 184:2389-2398.

Charity, J. C., Pak, K., Delwiche, C. F., and Hutcheson, S. W. 2003. Novel exchangeable effector loci associated with the Pseudomonas syringae hrp pathogenicity island: Evidence for integron-like assembly from transposed gene cassettes. Mol. Plant-Microbe Interact. 16:495-507.

Charkowski, A. O., Alfano, J. R., Preston, G., Yuan, J., He, S. Y., and Collmer, A. 1998. The Pseudomonas syringae pv. tomato HrpW protein has domains similar to harpins and pectate lyases and can elicit the plant hypersensitive response and bind to pectate. J. Bacteriol. 180:5211-5217.

Chen, C.-H., Lin, H.-J., and Feng, T.-Y. 1998. An amphipathic protein from sweet pepper can dissociate harpin ${ }_{\text {Pss }}$ multimeric forms and intensify the harpin $\mathrm{Pss}_{\mathrm{Ps}}$-mediated hypersensitive response. Physiol. Mol. Plant Pathol. 52:139-149.

El-Maarouf, H., Barny, M. A., Rona, J. P., and Bouteau, F. 2001. Harpin, a hypersensitive response elicitor from Erwinia amylovora, regulates ion channel activities in Arabidopsis thaliana suspension cells. FEBS (Fed. Eur. Biol. Soc.) Lett. 497:82-84.

Galan, J. E., and Collmer, A. 1999. Type III secretion machines: Bacterial devices for protein delivery into host cells. Science 284:1322-1328.

He, S. Y., Huang, H.-C., and Collmer, A. 1993. Pseudomonas syringae pv. syringae harpin ${ }_{\mathrm{Pss}}$ : A protein that is secreted via the Hrp pathway and elicits the hypersensitive response in plants. Cell 73:1255-1266.

Hoyos, M. E., Stanley, C. M., He, S. Y., Pike, S., Pu, X.-A., and Novacky,

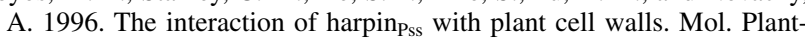
Microbe Interact. 9:608-616.

Håkansson, S., Schesser, K., Persson, C., Galyov, E. E., Rosqvist, R., Homble, F., and Wolf-Watz, H. 1996. The YopB protein of Yersinia pseudotuberculosis is essential for the translocation of Yop effectors across the target cell plasma membrane and displays a contact dependent membrane disrupting activity. EMBO (Eur. Mol. Biol. Organ.) J. 15:5812-5823.

Jin, Q., and He, S. Y. 2001. Role of the Hrp pilus in type III protein secretion in Pseudomonas syringae. Science 294:2556-2558.

Koivunen, E., Ranta, T.-M., Annila, A., Taube, S., Uppala, A., Jokinen, M., van Willigen, G., Ihanus, E., and Gahmberg, C. G. 2001. Inhibition of $\beta_{2}$ integrin-mediated leucosyte cell adhesion by leucine-leucine-glycine motif-containing peptides. J. Cell Biol. 153:905-915.

Lee J., Klessig, D. F., and Nürnberger, T. 2001a. A harpin binding site in tobacco plasma membranes mediates activation of the pathogenesisrelated gene HIN1 independent of extracellular calcium but dependent on mitogen-activated protein kinase activity. Plant Cell 13:1079-1093.

Lee, J., Klüsener, B., Tsiamis, G., Stevens, C., Neyt, C., Tampakaki, A. P., Panopoulos, N. J., Nöller, J., Weiler, E. W., Cornelis, G. R., Mansfield, J. W., and Nürnberger, T. 2001b. HrpZ $Z_{\mathrm{Psph}}$ from the plant pathogen Pseudomonas syringae pv. phaseolicola binds to lipid bilayers and forms an ion-conducting pore in vitro. Proc. Natl. Acad. Sci. U.S.A. 98:289-294.

Li, C.-M., Brown, I., Mansfield, J., Stevens, C., Boureau, T., Romantschuk, M., and Taira, S. 2002. The Hrp pilus of Pseudomonas syringae elongates from its tip and acts as a conduit for translocation of the effector protein HrpZ. EMBO (Eur. Mol. Biol. Organ.) J. 21:1909-1915.

Pike, S. M., Ádám, A. L., Pu, X.-A., Hoyos, M. E., Laby, R., Beer, S. V., and Novacky, A. 1998. Effects of Erwinia amylovora harpin on tobacco leaf cell membranes are related to leaf necrosis and electrolyte leakage and distinct from perturbations caused by inoculated E. amylovora. Physiol. Mol. Plant Pathol. 53:39-60.

Preston, G., Huang, H.-C., He, S. Y., and Collmer, A. 1995. The HrpZ proteins of Pseudomonas syringae pvs. syringae, glycinea, and tomato are encoded by an operon containing Yersinia ysc homologs and elicit the hypersensitive response in tomato but not soybean. Mol. Plant-Microbe Interact. 8:717-732.

Rantakari, A., Virtaharju, O., Vähämiko, S., Taira, S., Palva, E. T., Saarilahti, H. T., and Romantschuk, M. 2001. Type III secretion contributes to the pathogenesis of the soft-rot pathogen Erwinia carotovora: Partial characterization of the hrp gene cluster. Mol. Plant-Microbe Interact. 14:962-968.

Roine, E., Wei, W., Yuan, J., Nurmiaho-Lassila, E.-L., Kalkkinen, N., Romantschuk, M., and He, S. Y. 1997. Hrp pilus: An hrp-dependent bacterial surface appendage produced by Pseudomonas syringae pv. tomato DC3000. Proc. Natl. Acad. Sci. U.S.A. 94:3459-3464.

Taguchi, F., Tanaka, R., Kinoshita, S., Ichinose, Y., Imura, Y., Andi, S., Toyoda, K., Shiraishi, T., and Yamada, T. 2001. Harpin ${ }_{\text {Psta }}$ from Pseudomonas syringae pv. tabaci is defective and deficient in its expression and HR-inducing activity. J. Gen. Plant Pathol. 67:116-123.

Tampakaki, A. P., and Panopoulos, N. J. 2000. Elicitation of hypersensitive cell death by extracellularly targeted $\mathrm{HrpZ}_{\mathrm{Psph}}$ produced in planta. Mol. Plant-Microbe Interact. 13:1366-1374.

Wei, Z.-M., Laby, R. J., Zumoff, C. H., Bauer, D. W., He, S. Y., Collmer, A., and Beer, S. V. 1992. Harpin, elicitor of the hypersensitive response produced by the plant pathogen Erwinia amylovora. Science 257:85-88. 